\title{
Cassava farming practices and their agricultural and environmental impacts: a systematic map protocol
}

\author{
Gorm E. Shackelford ${ }^{1 *}$ (D, Neal R. Haddaway ${ }^{2,3}$, Hope O. Usieta ${ }^{4}$, Pieter Pypers ${ }^{5}$, Silviu O. Petrovan ${ }^{1}$ \\ and William J. Sutherland ${ }^{1}$
}

\begin{abstract}
Background: Cassava (Manihot esculenta) is a staple crop that is important for food security in the tropics. However, cassava farming can have severe environmental impacts, such as habitat destruction and soil degradation, if it is not carefully managed. Therefore, a wide range of agricultural and environmental outcomes should be considered when cassava farming practices are recommended as "good agricultural practices". We propose a systematic map of research on cassava farming practices and their impacts on yield, quality, profitability, soil, water, wildlife, pathogens, pests, weeds, and other agricultural and environmental outcomes. This map will improve our knowledge of the multifunctionality of cassava farming practices, by answering several questions: Which studies have measured the impacts of cassava farming practices on agricultural and/or environmental outcomes? Which practices and outcomes have been studied, in which countries, and when?
\end{abstract}

Methods: We will search for studies of "cassava OR mandioca OR manihot OR manioc OR yuca" in four publication databases (AGRICOLA, AGRIS, Scopus, Web of Science), two repositories of grey literature (including publications from the International Center for Tropical Agriculture and the International Institute of Tropical Agriculture, which have worked extensively on cassava), and the Conservation Evidence database. We will screen the search results using eligibility criteria that are transparently reported and consistently applied. We will not critically appraise the validity of the studies that are included in the map, because we see this map as a subject-wide evidence base that could be used for multiple methods of evidence synthesis, with different criteria for critical appraisal. We have developed a classification of agricultural practices and a classification of agri-environmental outcomes, and we will use these classifications ("taxonomies" or "terminological ontologies") when coding studies. We have developed a web application (http:// www.metadataset.com) with drop-down menus for screening and coding. We will analyse the number of studies by practice, outcome, country, and year, and we will present the results as a searchable database with interactive geographical maps (an "evidence atlas") that will show knowledge gaps and knowledge clusters.

Keywords: Agroecological practices, Agricultural management practices, Best management practices, Classification systems, Good agricultural practices, Multifunctionality, Recommended management practices, Subject-wide evidence synthesis, Sustainable agriculture, Sustainable intensification

\footnotetext{
*Correspondence: gorm.shackelford@gmail.com; ges47@cam.ac.uk

${ }^{1}$ Conservation Science Group, David Attenborough Building, Department

of Zoology, University of Cambridge, Cambridge CB2 3QZ, UK

Full list of author information is available at the end of the article
} 


\section{Background}

Cassava (Manihot esculenta), also known as mandioca, manioc, and yuca, is a woody perennial plant in the spurge family (Euphorbiaceae) [1]. Cassava is native to South America [2], but it is grown throughout the tropics and subtropics (Fig. 1). Cassava has been called "the drought, war, and famine crop" because it can be grown in challenging conditions (e.g., dry soils with low fertility) and it can be harvested when needed (i.e. not only at the end of the growing season), providing a reserve of food in times of war and famine [3]. It has also been suggested that cassava could be more resilient to climate change than other staple crops [4]. Average cassava yields (e.g., root yields of $11.6 \mathrm{t} /$ ha worldwide, in the 5 years from 2011 to 2015 [5]) are much lower than potential cassava yields, but better farming practices could help to close these yield gaps (e.g., root yields of $60 \mathrm{t} /$ ha have been reported in parts of Africa) [6, 7].

Improvements in cassava yield, quality, and sustainability could be important for food security in Africa, where the human population is expected to double by 2050 [8]. These improvements could be especially important in Nigeria, where more cassava is produced than in any other country, but where cassava yields are low (Table 1), and where the human population is expected to increase faster than in any other country [8]. However, the

\section{a \\ Cassava production \\ (Mt/year, 2011-2015) \\ $0.001-1$ \\ $1-10$ \\ $10-20$ \\ 20-30 \\ 30-40 \\ 40-50 \\ 50-60 \\ b \\ Cassava yield \\ (t/ha, 2011-2015) \\ 1-5 \\ 5-10 \\ 10-15 \\ 15-20 \\ 20-25 \\ 25-30 \\ 30-35}

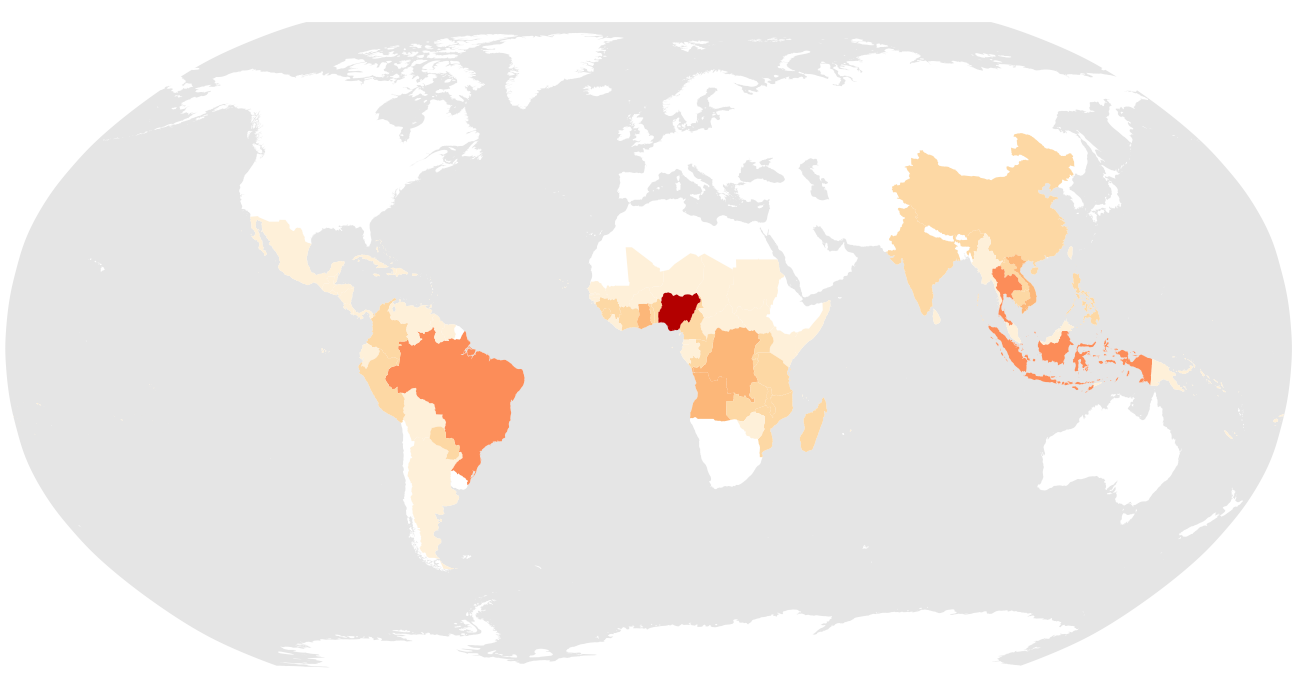

Fig. 1 Cassava statistics by country (mean values in 2011-2015): a cassava production (Mt/year) and b cassava yield (t/ha), based on data from FAOSTAT [5] 
Table 1 The top ten cassava producers in the world, ranked by mean cassava production in 2011-2015 (same data as Fig. 1)

\begin{tabular}{llc}
\hline Country & $\begin{array}{l}\text { Cassava production (Mt/ } \\
\text { year) }\end{array}$ & $\begin{array}{l}\text { Cassava } \\
\text { yield (t/ } \\
\text { ha) }\end{array}$ \\
\hline Nigeria & 52 & 9 \\
Thailand & 29 & 22 \\
Indonesia & 23 & 22 \\
Brazil & 23 & 14 \\
Ghana & 16 & 18 \\
Democratic Republic of the & 15 & 8 \\
Congo & 11 & 12 \\
Angola & 10 & 18 \\
Viet Nam & 8 & 24 \\
Cambodia & 8 & 8 \\
Mozambique & & \\
\hline
\end{tabular}

intensification and expansion of cassava production in Africa will need to be carefully managed to minimize its environmental impacts $[9,10]$. For example, the Guinea Savannah has been seen as an unexploited opportunity for the expansion of commercial cassava production, in spite of the potential for environmental impacts [11]. If it is not carefully managed, cassava farming can cause habitat destruction and soil degradation, as forests and other natural habitats are cleared and replaced by cassava farms, and soils are eroded and depleted of nutrients $[9,11]$. These impacts are not necessarily worse than the impacts of other crops, but more sustainable methods of cassava farming could provide substantial environmental benefits, since cassava is a staple crop that is grown over a substantial proportion of tropical cropland.

The dual aims of increasing food production and reducing environmental impacts have led to calls for the "sustainable intensification" or "ecological intensification" of food production through the use of "good agricultural practices" [12, 13]. To support the use of good agricultural practices through access to scientific knowledge, we propose a systematic map [14] of studies about cassava farming.

Agricultural extension manuals for cassava farmers are already available from international authorities on cassava farming, such as the International Center for Tropical Agriculture (CIAT), the International Institute of Tropical Agriculture (IITA), and the Food and Agriculture Organization (FAO) of the United Nations (e.g., [15-17]). The recommended management practices in these extension manuals are based on decades of scientific studies and expert opinions. However, what is not available in these manuals, or elsewhere, is a systematic map of these scientific studies. Based on this systematic map, systematic reviews, meta-analyses, and other forms of evidence synthesis [18] could be used to summarize the impacts of these recommended management practice on multiple outcomes (and not only agricultural outcomes, but also environmental outcomes). Thus, this map could be used as the foundation for a method known as "subject-wide evidence synthesis" [19] (simultaneous evidence synthesis for multiple interventions and multiple outcomes across a wide subject area), and the recommended management practices in agricultural extension manuals could be transparently and robustly based on this evidence. This subject-wide evidence synthesis could also be used to evaluate the multifunctionality of these recommended management practices (e.g., through multiple-criteria decision analysis [20], based on evidence of multiple outcomes).

\section{Stakeholder engagement}

This protocol has been developed in consultation with the Leventis Foundation, which has provided the funds for this map and which runs agricultural schools [21] in Nigeria and Ghana, the African Cassava Agronomy Initiative (ACAI) [22], and the Conservation Evidence group at the University of Cambridge [23], all of which could be considered stakeholders in this map. The authors of this protocol include leaders from each of these groups of stakeholders (HOU, PP, and WJS), and we expect this map to be useful to each of these groups, as well as other stakeholders in Africa and further afield. For example, this map could be used to prioritize primary research on knowledge gaps or secondary research on knowledge clusters. The Conservation Evidence Synopsis on Farmland Conservation [24] was based on a systematic map that was published in Environmental Evidence [25], and the systematic map that we are proposing could be used to support a similar synopsis on sustainable cassava farming. A Conservation Evidence Synopsis is a form of subject-wide evidence synthesis in which narrative summaries of scientific studies are written in a standardized form (typically one paragraph per study, with information on study location, study design, methods, and results), but quantitative summaries (e.g., meta-analysis) could also be used for subject-wide evidence synthesis.

\section{Objective of the systematic map Primary objectives}

The primary objectives of this systematic map will be to answer the following questions.

1. Which studies have measured the impacts of cassava farming practices (i.e. interventions/exposures) on cassava yield, quality, or profitability, soil, water, wild- 
life, pathogens, pests, or weeds (i.e. outcomes) in cassava fields?

2. Which practices and outcomes have been studied?

3. Which countries have been studied, and when?

4. What is the distribution and abundance of studies between different practices, outcomes, countries, and years? In other words, where are the knowledge gaps or knowledge clusters in this map?

\section{Secondary objectives}

The secondary objectives of this systematic map will be to test the usability of (1) a classification of farming practices, and (2) a classification of agricultural and environmental outcomes, both of which could be reused for systematic maps of other crops. These classifications are hierarchical representations of farming practices or agrienvironmental outcomes (i.e. they are "taxonomies" or "terminological ontologies" [26]).

\section{Methods}

These methods are based on the Collaboration for Environmental Evidence (CEE) guidelines for systematic mapping [14], and a ROSES checklist (RepOrting standards for Systematic Evidence Synthesis) [27] has been completed (Additional file 1).

\section{Searches}

We will search for evidence using the following search string: "cassava OR mandioca OR manihot OR manioc OR yuca" (cassava and its common synonyms $[1,28]$ ). We will use this search string for all of our searches (see below). We will not include search terms for cassava products (e.g., "gari" or "tapioca"). Systematic reviews are typically focused on narrow or "closed-framed" questions, such as "What are the effects of intervention $\mathrm{X}$ on subject Y?" [14]. Therefore, systematic reviews typically search for publications that contain at least one synonym from each "concept" in the research question (e.g., each subject and each intervention) [29]. For example, if we were only interested in the effects of tillage in cassava fields, we could limit our search to "tillage AND (cassava OR mandioca OR manihot OR manioc OR yuca)". However, our objective here is wider and more "open-framed" than that of a systematic review. We want to systematically map the impacts of multiple interventions on multiple outcomes.

By not using search terms for any specific interventions, our search string could be expected to have low "specificity" (e.g., a low proportion of publications about farming interventions, as opposed to interventions for processing or using cassava as an industrial starch) and high "sensitivity" (e.g., a high number of all publications about cassava farming). However, we have tested the specificity of the search string, and we expect about $8-10 \%$ of non-duplicated search results to be included in the map. This is a much higher percentage than the average systematic map in Environmental Evidence (with a mean of 423 full texts included from 22,636 non-duplicated search results, or about $2 \%$ of unique results [30]), and thus we expect our search string to have relatively high specificity. This is not surprising, because we expect to include almost all field studies of cassava farming practices (see below). However, by using a search string that we expect to be highly sensitive, we cannot systematically collect a benchmark set of publications to test the sensitivity of the search string, without using the search string itself (e.g., without searching for "cassava" or its synonyms).

\section{Publication database searches}

We will search two generic databases (Scopus and the Web of Science Core Collection) and two subject-specific (agricultural) databases (AGRICOLA and AGRIS). The two generic databases mostly include peer-reviewed academic publications, but the two subject-specific databases also include grey literature. We will also search a database of publications about conservation interventions (Conservation Evidence).

\section{Internet searches}

We will search the first 500 results from one search engine (Google Scholar, sorted by "relevance"). This method has been shown to be useful for finding both academic and grey literature [31].

\section{Specialist searches}

We will search for additional publications (including grey literature) in two repositories: the first 500 results from the repository of the Consultative Group on International Agricultural Research (CGIAR) Centers, in CGSpace: A Repository of Agricultural Research Outputs (sorted by "relevance"), and the first 500 results from the Document Repository of the FAO (sorted by "relevance"). CGSpace includes publications from multiple organizations, including CIAT, IITA, Bioversity International, and the CGIAR Research Program on Roots, Tubers and Bananas.

\section{Screening}

We will screen publications in two stages: (1) using titles and abstracts and (2) using full texts. At each stage, we will decide whether to include or exclude a publication in the map, based on the eligibility criteria (see below). We will record the number of publications included/excluded at each stage, and we will provide a list of the full texts 
that were excluded, together with reasons for exclusion and a ROSES flow diagram [27]. We will only include publications that are written in English. We acknowledge that this is a limitation, but we do not have the resources needed to work in other languages, and the stakeholders that plan to use this map will use it in English-speaking countries (Nigeria, Ghana, Kenya, and the United Kingdom). However, we will provide a list of excluded publications that are not in English, should resources become available to include these publications in an updated map.

For consistency checking, $10 \%$ of titles/abstracts (selected at random) will be screened by two people. Based on our scoping searches, we expect about 20,00025,000 non-duplicated search results, and thus we expect about 2000-2500 titles/abstracts to be screened by two people. Disagreements between these two people will be discussed, and the eligibility criteria will be revised to show how these disagreements were resolved. Kappa scores will then be calculated to test the agreement between these two people [32]. If the Kappa scores are less than 0.6 , then another $1 \%$ of titles/abstracts will be screened by two people. Disagreements will be discussed and resolved again, Kappa scores will be calculated again, and this process will be repeated until the Kappa scores are greater than 0.6. All other publications will be screened by one person.

\section{Eligibility criteria}

We use "PICO/PECO" terminology ("P" = populations/ subjects, "I" = interventions/"E" = exposures, "C" $=$ comparators, "O"=outcomes) to define the eligibility criteria [14]. We will include any study that measured the impacts of a cassava farming practice on an agricultural or environmental outcome (see below for definitions of "interventions/exposures" and "outcomes"). We will exclude studies in laboratories and other studies that are not in cassava fields, cassava plots, or cassava pots with reasonably realistic production conditions (e.g., not cassava pots in greenhouses/screenhouses stocked with pests and/or natural enemies). For example, we will exclude laboratory studies of genetic diversity, but we will include field studies in which genetically improved cultivars are compared to local varieties. We will also exclude studies of the post-harvest management of cassava (e.g., storing and processing cassava), but we will include studies of the post-harvest management of cassava fields (e.g., cover cropping or reduced tillage). We will provide a list of publications that were excluded at full-text stage with reasons for exclusion.

\section{Populations/subjects}

We will include studies of the effects of cassava farming practices on soil, water, wildlife, pathogens, pests, and weeds, measured in cassava fields/plots/pots, or in farming landscapes that include cassava (e.g., field margins or watercourses adjacent to cassava fields), anywhere in the world. We will also include studies of the effects of cassava farming practices on cassava itself (e.g., cassava yield, quality, and profitability). We will not include studies of the effects of cassava farming practices on livestock.

\section{Interventions/exposures}

All in-field/on-farm management practices will be included. We have developed a provisional classification of farming practices (Additional file 2), based on the "agroecological practices" that were classified by Wezel et al. [33] and our recent review of farming practices [34]. We will include studies that measured the impacts of any of these practices on agricultural or environmental outcomes (see below). If we find additional practices when we are screening publications, then we will add these practices to the classification and include these studies in the systematic map (but only for practices in cassava fields/plots/pots, and only for effects on the above populations/subjects and not effects on livestock). We want to develop a classification that is not specific only to cassava but is generalizable to other crops and thus is reusable (such that data and metadata can be coded using a consistent classification). This systematic map will help us to test this classification.

\section{Comparators}

We will include controlled studies (e.g., plots with an intervention compared to plots without an intervention, or plots with a "conventional" intervention compared to plots with an "alternative" intervention, such as "conventional tillage" compared to "reduced tillage"). We will also include correlated studies (e.g., comparisons of sites that are correlated with different interventions, such as planting cassava in different agroecological zones), and before-and-after studies. Thus, the comparator could be a control or a counterfactual (spatial or temporal), and we will not exclude studies unless there are no comparators at all.

\section{Outcomes}

We will include studies of all environmental/ecological and agricultural outcomes. We have developed a provisional classification of outcomes (Additional file 3), based on our recent review of evidence for the impacts of farming practices [34]. If we find additional outcomes for these populations/subjects when we are screening publications, then we will add these outcomes to the classification and include these studies in the systematic map. Note that we will not include outcomes for livestock, or for the adoption of cassava farming practices by farmers, 
both of which we see as separate subjects that are beyond the scope of this map. Like our classification of farming practices, we also want to develop a classification of outcomes that is reusable for other crops. There are "n.e.c." classes that can be used if an outcome or intervention/ exposure is "not elsewhere classified" in either of these classifications, and we will either use these n.e.c. classes or else we will create additional classes if we find additional outcomes or intervention/exposures.

\section{Study design}

We will only include studies that measured the effects of an intervention/exposure on an outcome and also reported the numerical results of these measurements in a figure or a table (e.g., means of treatment plots and control plots). We will only include studies from primary literature, not secondary literature. Secondary literature will be defined as a publication in which another publication is cited as the source of these numerical results. We will provide a list of studies that are excluded as secondary literature. If possible, we will code an intervention/ exposure as "controlled" or "correlated" (see comparators, above), "blocked", "randomized", and/or "replicated". For example, a "randomized complete block" design (a common design in field trials) will be coded as "blocked", "randomized", "replicated", and "controlled".

\section{Study validity assessment}

Because this is a systematic map, not a systematic review, we will not critically appraise the validity of these studies [14]. We see this map as a subject-wide evidence base that could be used for multiple methods of evidence synthesis, with different criteria for critical appraisal in each case. For example, a systematic review that is based on this map might only include studies that statistically tested the effects of an intervention on an outcome, but the map will include studies that reported numerical results with or without statistical tests.

\section{Data coding}

We will code PICO/PECO components (Additional files 2 , 3), study location(s), and study year(s). This metadata will be entered into a database, using data-entry forms with $\mathrm{PICO} / \mathrm{PECO}$ components and countries in dropdown menus (to minimize errors). We have developed a web application for this purpose (http://www.metadatase t.com). The drop-down menus will require $\mathrm{PICO} / \mathrm{PECO}$ components to be selected in stages, to simplify the number of options at each stage (e.g., only the first two levels of the hierarchical classification of farming practices will be shown in the first menu). To check the consistency of data coding, the metadata from 50 publications (at the full-text stage, selected at random) will be coded by two people. Kappa scores will be calculated to test the agreement between these two people (i.e. agreement about which practices and outcomes were studied). Disagreements will be discussed, and the eligibility criteria will be revised to show how these disagreements were resolved. If the Kappa scores are less than 0.6 (as above), then the metadata from another 10 publications will be coded by two people. Kappa scores will be calculated again, and this process will be repeated until the Kappa scores are greater than 0.6 . The metadata for all other publications will be coded by one person. These tests will help us to improve the usability of our classification systems.

\section{Study mapping and presentation}

We will analyse the number of publications by practice, outcome, country, and year and we will present the results as a searchable database with interactive geographical maps (an "evidence atlas" [35]) that will show knowledge gaps and knowledge clusters. We will also present the number of publications by practice and outcome in tables (based on Additional files 2, 3). We will also consider the possibility of using machine learning and topic modelling to support the classification of publications $[36,37]$.

\section{Additional files}

Additional file 1. ROSES form.

Additional file 2. Classification of agricultural practices to be included in the systematic map.

Additional file 3. Classification of agricultural and environmental outcomes to be included in the systematic map.

\section{Authors' contributions}

GES, HOU, and WJS planned the research. GES wrote the manuscript. All authors revised the manuscript. All authors read and approved the final manuscript.

\section{Author details \\ ${ }^{1}$ Conservation Science Group, David Attenborough Building, Department of Zoology, University of Cambridge, Cambridge CB2 3QZ, UK. ${ }^{2}$ Stockholm Environment Institute, Linnégatan 87D, Box 24218, 10451 Stockholm, Sweden. ${ }^{3}$ Africa Centre for Evidence, University of Johannesburg, Johannesburg, South Africa. ${ }^{4}$ Leventis Foundation (Nigeria), 2 Leventis Close, Central Business Dis- trict, Federal Capital Territory, Abuja, Nigeria. ${ }^{5}$ International Institute of Tropical Agriculture (IITA), IITA-ICIPE Office, P.O. Box 30772-00100, Nairobi, Kenya.}

\section{Acknowledgements}

We thank Alexander Wezel and Nick Salafsky for comments on our provisional classification of agricultural practices.

\section{Competing interests}

The authors declare that they have no competing interests. The systematic mappers will not have authored any publications that are relevant to this map and therefore they will not review their own publications.

Availability of data and materials

Not applicable. 


\section{Consent for publication \\ Not applicable.}

\section{Ethics approval and consent to participate}

Not applicable.

\section{Funding}

We thank the A. G. Leventis Foundation and Arcadia for funding.

\section{Publisher's Note}

Springer Nature remains neutral with regard to jurisdictional claims in published maps and institutional affiliations.

Received: 6 June 2018 Accepted: 3 December 2018

Published online: 15 December 2018

\section{References}

1. Hillocks RJ, Thresh JM, Bellotti AC, editors. Cassava biology, production and utilization. Wallingford: CABI Publishing; 2002.

2. Allem AC. The origins and taxonomy of cassava. In: Hillocks RJ, Thresh JM, Bellotti AC, editors. Cassava: biology, production and utilization. Wallingford: CABI Publishing; 2002. p. 1-16.

3. Burns A, Gleadow R, Cliff J, Zacarias A, Cavagnaro T. Cassava: the drought, war and famine crop in a changing world. Sustainability. 2010;2:3572-607.

4. Jarvis A, Ramirez-Villegas J, Campo BVH, Navarro-Racines C. Is cassava the answer to African climate change adaptation? Tropical Plant Biology. 2012;5:9-29.

5. FAO. FAOSTAT Database. Rome: Food and Agriculture Organization of the United Nations (FAO); 2018. http://www.fao.org/faostat/.

6. Kintché K, Hauser S, Mahungu NM, Ndonda A, Lukombo S, Nhamo N, et al. Cassava yield loss in farmer fields was mainly caused by low soil fertility and suboptimal management practices in two provinces of the Democratic Republic of Congo. Eur J Agron. 2017;89:107-23.

7. Fermont AM, van Asten PJA, Tittonell P, van Wijk MT, Giller KE. Closing the cassava yield gap: an analysis from smallholder farms in East Africa. Field Crops Res. 2009;112:24-36.

8. UN. World Population Prospects: The 2017 Revision, Key Findings and Advance Tables. New York: Department of Economic and Social Affairs (DESA) of the United Nations (UN), Population Division; 2017.

9. Reynolds TW, Waddington SR, Anderson CL, Chew A, True Z, Cullen A. Environmental impacts and constraints associated with the production of major food crops in Sub-Saharan Africa and South Asia. Food Secur. 2015;7:795-822

10. Shackelford GE, Steward PR, German RN, Sait SM, Benton TG. Conservation planning in agricultural landscapes: hotspots of conflict between agriculture and nature. Divers Distrib. 2015;21:357-67.

11. Morris ML, Binswanger-Mikhize HP, Byerlee D. Awakening Africa's sleeping giant: prospects for commercial agriculture in the Guinea Savannah Zone and beyond. Washington, D. C.: The World Bank; 2009.

12. Pretty J, Toulmin C, Williams S. Sustainable intensification in African agriculture. Int J Agric Sustain. 2011;9:5-24.

13. Doré T, Makowski D, Malézieux E, Munier-Jolain N, Tchamitchian M, Tittonell P. Facing up to the paradigm of ecological intensification in agronomy: revisiting methods, concepts and knowledge. Eur J Agron. 2011;34:197-210

14. James KL, Randall NP, Haddaway NR. A methodology for systematic mapping in environmental sciences. Environ Evid. 2016;5:7.

15. Howeler R, Lutaladio N, Thomas G. Save and Grow: Cassava. A guide to sustainable production intensification. 2013.

16. Atser G, Dixon A, Ekeleme F, Chikoye D, Dashiell K, Ayankanmi T, et al. The $A B C$ of weed management in cassava production in Nigeria: a training manual. Ibadan, Nigeria: International Institute of Tropical Agriculture (IITA); 2017.
17. Howeler R, Aye TM. Sustainable Management of Cassava in Asia: From Research to Practice. Cali, Columbia: International Center for Tropical Agriculture (CIAT); 2014.

18. Dicks L, Haddaway N, Hernández-Morcillo M, Mattsson B, Randall N, Failler $P$, et al. Knowledge synthesis for environmental decisions: an evaluation of existing methods, and guidance for their selection, use and development: a report from the EKLIPSE project. 2017.

19. Sutherland WJ, Wordley CFR. A fresh approach to evidence synthesis. Nature. 2018;558:364

20. Adem Esmail B, Geneletti D. Multi-criteria decision analysis for nature conservation: a review of 20 years of applications. Methods Ecol Evol. 2018;9:42-53.

21. Osokoya MM. An assessment of the curriculum of Leventis Foundation (Nigeria) Agricultural Schools (LFNAS) Programme. Sustain Human Dev Rev. 2009;1:95-112

22. Pypers P. The African Cassava Agronomy Initiative (ACAI) project model. 2017. https://hdl.handle.net/10568/88115.

23. Sutherland WJ, Dicks LV, Ockendon N, Petrovan SO, Smith RK. What Works in Conservation: 2018. Open Book Publishers; 2018. https://www.conse rvationevidence.com

24. Dicks LV, Ashpole JE, Dänhardt J, James K, Jönsson AM, Randall N, et al. Farmland Conservation: Evidence for the effects of interventions in northern and western Europe. Pelagic Publishing Ltd; 2014. https://www.conse rvationevidence.com

25. Randall NP, James KL. The effectiveness of integrated farm management, organic farming and agri-environment schemes for conserving biodiversity in temperate Europe-a systematic map. Environ Evid. 2012;1:4.

26. Roussey C, Soulignac V, Champomier JC, Abt V, Chanet JP. Ontologies in Agriculture. In: AgEng 2010, International Conference on Agricultural Engineering, Sep 2010, Clermont-Ferrand, France. Clermont-Ferrand, France: Cemagref; 2010. https://hal.archives-ouvertes.fr/hal-00523508.

27. Haddaway NR, Macura B, Whaley P, Pullin AS. ROSES RepOrting standards for systematic evidence syntheses: pro forma, flow-diagram and descriptive summary of the plan and conduct of environmental systematic reviews and systematic maps. Environ Evid. 2018;7:7.

28. Gade DW. Names for Manihot esculenta: geographical variation and lexical clarification. J Latin Am Geogr. 2002;1:43-57.

29. Higgins JP, Green S, editors. Cochrane handbook for systematic reviews of interventions. New York: Wiley; 2011.

30. Haddaway NR, Westgate MJ. Predicting the time needed for environmental systematic reviews and systematic maps. Conserv Biol. 2018. https:// doi.org/10.1111/cobi.13231

31. Haddaway NR, Collins AM, Coughlin D, Kirk S. The Role of Google Scholar in evidence reviews and its applicability to grey literature searching. PLoS ONE. 2015;10:e0138237.

32. Cohen J. A coefficient of agreement for nominal scales. Educ Psychol Measur. 1960;20:37-46.

33. Wezel A, Casagrande M, Celette F, Vian J-F, Ferrer A, Peigné J. Agroecological practices for sustainable agriculture. A review. Agron Sustain Dev. 2014;34:1-20.

34. Shackelford GE, Kelsey R, Robertson RJ, Williams DR, Dicks LV. Sustainable Agriculture in California and Mediterranean Climates: Evidence for the effects of selected interventions. Cambridge, UK: University of Cambridge; 2017. https://www.conservationevidence.com.

35. Eales J, Haddaway NR, Bernes C, Cooke SJ, Jonsson BG, Kouki J, et al. What is the effect of prescribed burning in temperate and boreal forest on biodiversity, beyond pyrophilous and saproxylic species? A systematic review. Environ Evid. 2018;7:19.

36. Westgate MJ, Barton PS, Pierson JC, Lindenmayer DB. Text analysis tools for identification of emerging topics and research gaps in conservation science. Conserv Biol. 2015;29:1606-14.

37. Westgate MJ, Haddaway NR, Cheng SH, McIntosh EJ, Marshall C, Lindenmayer DB. Software support for environmental evidence synthesis. Nat Ecol Evol. 2018;2:588-90. 